\title{
Arreta-defizitaren eta hiperaktibitatearen nahasmendua lau urteko umeengan eta haurdunaldiko tabako-kontsumoa
}

\author{
Smoking during pregnancy and subsequent attention-deficit/hyperactivity \\ disorder in four year olds
}

\author{
Helene Ezquiaga Echezarreta ${ }^{1}$, Juan J. Aurrekoetxea Agirre ${ }^{1-2-3}$, Mercedes Espada ${ }^{4}$, Jesus \\ Ibarluzea Maurolagoitia ${ }^{1-2-3}$ \\ ${ }^{1}$ Euskal Herriko Unibertsitatea, UPV/EHU \\ ${ }^{2}$ Osasun Saila. Eusko Jaurlaritza. Donostia \\ ${ }^{3}$ Biodonostia Osasun Ikerketa Institutua. Donostia \\ ${ }^{4}$ Osasun Publikoko Laborategia. Eusko Jaurlaritza. Bilbo
}

ji.aurreko@gmail.com

\section{Laburpena}

Arreta-defizitaren eta hiperaktibitatearen nahasmendua (ADHN) umeengan arazo hedatua da gure gizartean. Haurdunaldian tabako-kontsumoarekin lotu izan da hainbat ikerketatan, baina lotura kausal hori ondo finkatu gabe dago gaur egun. Ikerketa honen helburua zera da: emakume haurdunen tabako-aztura eta haien haurdunalditik jaiotako 4 urteko umeen ADHNa ikertzea. ADHNari buruzko 323 umeren informazioa jaso zen. Prebalentzia \% 2,5ekoa izan zen. Mutilek arrisku handiagoa erakusten zuten ADHNa pairatzeko neskek baino. Maila sozial baxuko eta, batez ere, lehen mailako edo ikasketa gabeko gurasoen umeek ADHNaren arriskua areagotuta zeukaten. Kohorteikerketa honetan amei haurdunaldiaren 32. astean tabakoari buruzko eta hainbat aldagai sozioekonomikori buruzko galdeketa egin zitzaien. Gainera, gernuko lagin batean kotinina neurtu zitzaien. Umeak 4 urteko pediatria-kontrola egiteko kontsultara eramaten zituzten helduei ADHD DMS-IV galdesorta pasatu zitzaien. Bi azpieskala ditu DMS-IV galdesortak, arreta-defizita eta hiperaktibitatea/inpultsibitatea neurtzen dutenak, 0tik 27 puntu bitartean, bakoitzean. Menpeko aldagaien asimetria dela eta, erregresio binomial negatiboa erabili zen analisi estatistikorako. Haurdunaldian erretzen zutenen edo gernu-kotinina altua (> $100 \mathrm{ng} / \mathrm{ml}$ ) zeukaten amen umeek \% 1722 bitarteko arreta-defizita izateko arrisku handiagoa zuten (esangura estatistikorik gabe). Hiperaktibitatea edo inpultsibitatea ez zen lotzen estatistikoki amaren tabako-kontsumoarekin. Ikerketa honek adierazten du ADHNaren eta haurdunaren tabako-kontsumoaren arteko lotura ez dela handia, baldin badago ere. Lanaren mugen artean dago laginaren tabako-azturaren prebalentzia (\% 21ekoa haurdunaldiaren hasieran eta \% 12koa 32. astean) eta kopuru murritza (gehienez 12 zigarro egunean). Ikerketa gehiago beharko dira hipotesi hau ondo zehazteko.

Gako hitzak: Arreta-defizitaren eta hiperaktibitatearen nahasmendua; tabako-aztura; haurdunaldia; gernu-kotinina.

\section{Abstract}

Attention deficit hyperactivity disorder (ADHD) in children is a widespread problem in contemporary society. Its association with tobacco consumption during pregnancy has been extensively studied, but a causal relation has not been established. The aim of this study was to investigate the correlation between smoking during pregnancy and the incidence of ADHD in subsequently born 4-year olds. Information was obtained from 323 children. The observed prevalence of ADHD was $2.5 \%$. The boys showed a higher risk of having ADHD than the girls and children of parents from lower social classes or who had a low level of education showed an increased risk of developing ADHD. We documented the smoking habits of mothers at week 32 of their pregnancy and recorded the corresponding socioeconomic variables. In addition, cotinine was measured in urine samples. During the 4-year 
pediatric control visit, the ADHD DMS-IV questionnaire was given to the adult accompanying the child. The DMS-IV grades both attention deficit and hyperactivity-impulsivity on a scale ranging from 0 to 27 points. Due to the asymmetry of the dependent variables, negative binomial regression was carried out for statistical analysis. Children of mothers who smoked during pregnancy or had high urinary cotinine levels (> $100 \mathrm{ng} / \mathrm{ml}$ ) showed a 17-22\% higher risk of having attention deficit (not statistically significant). In contrast, hyperactivity-impulsivity was not associated with maternal smoking during pregnancy. The present study provides evidence for a lack of association between $A D H D$ and smoking during pregnancy. Among the limits of this study are the prevalence of smoking (21\% at the beginning of pregnancy and $12 \%$ at week 32) and the low number of cigarettes smoked (maximum 12 per day). More research will be needed to verify if more intense smoking habits can influence the prevalence of $A D H D$.

Key words: Attention deficit hyperactivity disorder; smoking; pregnancy; urinary cotinine

Bidalia: 2017ko abuztuaren 25ean.

http://doi.org/10.26876/osagaiz.2.2017.96

Onartua: 2017ko urriaren 4an.

\section{Sarrera}

Arreta-defizitaren eta hiperaktibitatearen nahasmendua (ADHN) jatorri neurobiologikoa duen haurtzaroko asaldu mentala da. Ezaugarri garrantzitsuenak atentzio-falta, hiperaktibitatea eta inpultsibitatea dira. Sintoma horiek, asaldu mentalen eskuliburu diagnostiko eta estatistikoaren (DMS-IV) irizpideen arabera, 6 hilabete baino gehiago iraun behar dute eta haurrak 7 urte bete baino lehen agertu behar izan dira. Mundu mailan \% 5eko prebalentziarekin azaltzen dela onartzen da, nahiz ikerketek emaitza zeharo ezberdinak erakutsi (1). Ikerketa batek, Espainia mailan, \% 6ko prebalentzia erakusten du (2).

Hala ere, asaldu honen diagnostikoa irizpide klinikoetan oinarritzen denez, prebalentziaren datuak aldakorrak izango dira irizpide kliniko, ebaluazio-metodo, lagin mota, informazio-iturri eta populazioaren ezaugarri soziokulturalen arabera. ADHNa kasu gutxitan agertzen da asaldu bakar baten moduan; kasuen \% 70ean beste asaldu psikiatriko batzuekin batera agertzen da, adibidez: arazo desafiatzaile-ezezkorrak, portaera-arazoak, antsietate-arazoak, loaren arazoak, tik-ak eta abar. ADHNa beste asaldu horiekin batera agertzen denean, diagnostikoa larriagotu, eboluzioa okertu eta tratamenduarekiko erantzuna txikitu egiten da. ADHNa, gaur egun, esparru klinikoan eta osasun publikoan garrantzi handia duen nahasmendua da lehen mailako arretatik beste espezialitate medikoetara egiten diren deribazioengatik baita arazo honek eskatzen duen laguntza hezitzailearengatik. ADHNaren konplexutasunagatik, zaila izan da asaldu honi kausa bakar bat ezartzea eta arazo heterogeneotzat hartzen da (2).

Ongi ezagutzen da arazo honek osagai heredagarri garrantzitsua duela (batez besteko \% 79), baina faktore genetikoez gain gaixotasunean eragin dezaketen beste hainbat ingurune-faktore deskribatu dira: burualdeko traumatismoak, NSZko infekzioak, entzefalopatia hipoxiko-iskemikoa, jaiotzean pisu baxua, erditze goiztiarrak, zilbor-hestearen prolapsoa, preeklampsia, haurdunaldian zeharreko gernubideetako infekzioak, alkohol-kontsumoa, amaren estresa, baldintza sozioekonomikoak, etab. (1). Ikerketa berri baten arabera, herentziaz gain, ingurumeneko beste kutsatzaile batzuek eragina eduki lezakete; garrantzitsuena eta ikertuena nikotina izango litzateke (3).

Gai honen inguruan, ADHNan eragina izan dezaketen faktoreak azaltzeko erronka izan dute ikertzaile ugarik. Horrela, haurdunaldian tabakoa erretzea, ADHNa pairatzeko arrisku-faktore garrantzitsua dela aurkitu dute hainbat ikerketak. Baina horren harira, eztabaida ugari dago asoziazio hori tabakoak umetoki barnean eragiten dituen efektuengatik ote den (4). Aurretik egindako hainbat ikerlanen arabera, haurdunaldian zeharreko tabakoaren kontsumoak (batez ere amarenak) ADHNaren garapenean eragina zuela ikusteaz gain, tabakoren kontsumoak ez ezik, nikotina-txaplatek ere eragina zutela argitu zen $(5,6)$. Horretaz gain, kasu-kontrol ikerketa batek dio haurdunaldian erre zutenen haurrek portaera-arazo eta jokaera desafiatzaile eta borrokalari handiagoa zutela (7). 
Gainera, tabakoaren eragina dosiaren menpekoa dela ikusi da; beraz, geroz eta zigarro kopuru handiagoa kontsumitu, ADHNa izateko arriskua ere handiagoa izango da (8).

Hala ere, beste ikertzaile batzuek diote tabakoaren eta ADHNaren arteko erlazioan nahaste-faktoreek hartzen dutela parte, faktore genetikoek batez ere $(9,10,11)$. Azken horiek, ikerketa neba-arreben artean egitean eta aitaren tabako-kontsumoa ere kontuan hartuz, ez zuten ezberdintasun esanguratsurik ikusi; ezta zigarro-kontsumoa eta nikotina-ordezkoen eragina alderatzean ere.

Gure ikerketaren helburuak ondorengoak dira: lehenik, ADHNaren prebalentzia Gipuzkoako lagin batean ezagutzea, eta, bigarrenik, ADHNak haurdunaldiko tabako-esposizioarekin duen lotura ikertzea.

\section{Materiala eta metodoak}

\subsection{Populazioa eta lagina}

INMA (Infancia y Medio Ambiente, Haurtzaroa eta Ingurumena) Espainiako hainbat lurraldetako (Asturias, Valentzia, Sabadell, Menorca, Granada, Ribera de Ebro eta Gipuzkoa) jaiotzen kohorteikerketa prospektibo eta multizentrikoa da, ikerketa-talde ugarik osatzen dutena. Airean, uretan eta elikagaietan dauden kutsatzaileek umekian, jaioberrian eta umearen hazkuntzan nahiz garapenean eduki ditzaketen eraginak aztertu nahi izan dira proiektu horretan; xede hori lortu nahian sortu zen INMA. Ikerketa horren ebaluazio batean nondik norakoak argi azaltzen dira (12).

Gipuzkoan, 2006ko maiatzean jarri zen martxan proiektua. Emakumeak haurdunaldiko kontrolaren lehen ekografia egitean sartzen dira kohortean. Lagin biologikoak (odola, gernua, ilea, plazenta, eta abar) jasotzeaz gain, zenbait galdesorta (orokorra, gaixotasunak, dieta, lana, ingurugiroa, eta abar) betetzen dira, batetik, airean, ingurugiroan eta kontsumoko uretan aurkitzen diren kutsatzaileen balorazioa egiteko, eta, bestetik, dieta bidez jasotako kutsatzaileen estimazioa ateratzeko. Zumarragako Ospitaleari dagokion biztanleriak definitzen du ikerketaren inguru geografikoa, hau da, Goierriko eta Urola Garaiko nahiz Urola Erdiko udalerriek. Inguru hori aukeratu zen, hain zuzen, lehen mailako arreta eskaintzeagatik eta ospitaleko zerbitzuen ezaugarriengatik.

Zehazki, gure ikerketako datuak biltzeko, haurdunei 2006ko maiatzetik 2008ko urtarrilera arte egin zitzaien jarraipena. Ikerketan parte hartu ahal izateko, irizpideak hauek izan ziren: 16 urtetik gorakoa izatea, erreferentziazko ospitalean datuak emateko prest egotea, gaztelaniaz edo euskaraz komunikatzeko gai izatea, haurdunaldiak fetu bakarrekoak izatea eta lagundutako ugalketaprogramarik egin ez izana. Hasierako momentuan aukeratutako emakumeen \% 56k onartu zuten parte hartzea (kohorte guztiak kontuan harturik). Gipuzkoako kohortearen kasuan (gure lagina), parte-hartze ezaren arrazoiak jaso ziren: \% 27,6k ez zuen parte hartu nahi izan, \% 30,3k denborarik ez zuela esan zuen, \% 9,3k interesik ez zuela eta \% 32,7 ezin izan zen lokalizatu aukeratuak izan ondoren. Ikerketaren laginean umearen 4 urteko pediatriako kontrolean DSM-ADHD galdesorta bete zuten 323ak sartu ziren.

\subsection{ADHN Galdeketa}

ADHD-DMS-IV galdesortan, arreta-defizitaren eta hiperaktibitate/inpultsibitatearen azpieskalak aztertzen dira, eta bakoitzean 9 sintoma, item edo galdera bitartez, erantzunaren arabera 0 eta 3 arteko puntuazioa ematen zaio bakoitzari $(E z=0$, Noizbehinka $=1$, Askotan $=2$ eta Etengabe $=3$ ) (13). Hori horrela izanda, "Askotan» eta «Etengabe» erantzunetan sintoma hori positiboa dela kontsideratzen da eta sei sintoma edo gehiago daudenean ADHNaren diagnostikoa ezartzen da (Ebaketa-puntua $=6$; eta 12 puntu, gutxienez). Hori kontuan izanik, ADHNaren 3 azpimota ezberdintzen dira: 6 puntu baino gehiago lortzen badira bai arreta-defizitaren bai hiperaktibitate eta inpultsibitatearen galdeketetan, ADHN mota nahasia diagnostikatuko da (ADHNN); aldiz, 6 puntu baino gehiago soilik galdeketa batean lortzen badira, arreta-defizitaren nagusitasuna (ADHNA) edo hiperaktibitate-inpultsibitatearen nagusitasuna duen ADHNaren (ADHNH) diagnostikoa egingo da (2). Ikerketa honetan, hala ere, analisi estatistikorako ez genuen kasu/ez-kasu erabili menpeko aldagai bezala, ez eta sintoma kopuruena ere, baizik eta 0-1-2-3 puntuek ematen zuten puntuazio orokorra 
erabili zen; hau da, azpieskala bakoitzean 0tik 27ra bitartean aterako ziren puntuazioak aldagai jarraitu bezala erabili ziren, eta 0tik 54ra bitartean ADHNrako. Horrek aldakortasun handiagoa ematen dio menpeko aldagaiari.

\subsection{Tabakoari buruzko informazioa}

Tabakoaren inguruko informazioa lortzeko galdeketa bat pasa zitzaien amei, 32. astean, gurasoen kontsumoaren aurrekariak eta maiztasuna jakiteko. Lan honetarako haurdunaldiaren hasieran, haurdunaldiaren 12. astean eta 32. astean erretzen zuen (bai/ez) bildu zen, haurdunaldiaren momentu ezberdinen eragin posiblea ebaluatzeko. Galdesortaz gain, gernuko kotinina mailak ere neurtu ziren haurdunaldiaren 32. astean. Kotinina nikotinaren metabolito nagusia da eta azken bi egunen tabako aktiboaren zein pasiboaren informazio objektiboa ematen du (22-24 orduko batez besteko bizitza organismoan). Bilboko Osasun Publikoko Laborategian EIA microplate test kit-a (OsaRure Technologies Inc, Bio-Rad) erabili zen. Probaren kuantifikazio-muga [LOQ] $4 \mathrm{ng} / \mathrm{ml}$ zen, eta tabakoaren kutsaduraren adierazle espezifikoa denez, muga horren azpitik esposizio-eza kontsidera dezakegu; $4 \mathrm{ng} / \mathrm{ml}$-tik $99 \mathrm{ng} / \mathrm{ml}$-ra esposizio pasiboa adierazten digu, eta $100 \mathrm{ng} / \mathrm{ml}$ edo gehiago tabako aktiboa adierazten digu (14).

\subsection{Beste aldagaiak}

ADHNarekin lotura eduki dezaketen beste aldagai batzuen informazioa bildu zen: umearen sexua; haurdun geratzean amaren adina, lau kategoriatan banatuta $(<25 ; 25-29 ; 30-34 ; 35+)$; eta amaren eta aitaren klase soziala, lanpostuan oinarritua (I eta II elkartuta, III eta IV-V integratuz) [I-II: maila sozial altuena: enpresaburuak eta goi-mailako teknikariak, III: ertaina: eskulangile ez direnak, eta IVV: baxuena: eskulangileak]; eta ikasketa-maila: ikasketarik gabe edo oinarrizkoak, bigarren mailakoak eta unibertsitate-ikasketak dituztenak.

\subsection{Analisi estatistikoa}

Lagina deskribatzeko eta tabakoaren aztura zein esposizio pasiboa erakusteko frekuentzia absolutuak eta erlatiboak erabili ziren. ADHNaren eskala eta azpieskalen banaketa erakusteko batez bestekoa eta desbiderapen estandarra, eta banaketa ez-normala erakusten duenez, balio minimoa eta maximoa eta 25-50-75 pertzentilak erabili ziren. Asimetria horrengatik analisi estatistikorako erregresio linealaren ordez (aldagaiaren normaltasunean oinarritzen baita), erregresio binomial negatiboa erabili zen. Horrek, puntu batetik hurrengora pasatzeko probabilitatearen areagotzea adierazten digun adds ratioa (OR) eta \% 95eko konfiantza-tartea (\% $95 \mathrm{KT}$ ) kalkulatzen ditu. Analisi bibariantea egin zen soilik, aldagai sozioekonomikoak sartzean eredu anizkoitzean emaitzak ez zirelako modu nabarmenean aldatzen ( $\geq \% 10$ ean). Esangura-maila bezala $p<0,05$ erabili zen. Analisirako SPSS 22 bertsioa (IBM SPSS Statistics, IBM Corporation, Chicago, IL) erabili zen.

\section{Emaitzak}

ADHNaren 323 umeren informazioa jaso zen, 162 neska eta 161 mutil. Haurdun geratzean amen ia erdiek 30-34 urte zituzten. Amen \% 52k unibertsitate-ikasketak zituen, baina \% 40 maila sozial baxukoak ziren, eskulangileak, hain zuzen. Aiten ikasketak baxuagoak ziren, gehienak, \% 48,8, bigarren mailakoak eta \% 26,6 unibertsitarioak, eta gehienak ere, \% 57,8, eskulangileak ziren (1. taula). \% 2ra ez zirenez iristen 25 urtetik beherakoak beste analisietarako hurrengo adinmultzokoekin integratu genituen.

2. taulak tabakoaren azturaren berri ematen digu lagineko amen haurdunaldian. Haurdunaldiaren hasieran \% 21ek erretzen zuela adierazten zuen; bigarren hiruhilekoan \% 13ra jaitsi zen eta hirugarren hiruhilekoan \% 12ra; eta haien artean 12 zigarro egunean gehienez erretzen zutela aipatu zuten (tauletatik kanpoko informazioa). Gernu-kotininari dagokionez, \% 12k ere erretzailetzat hartzeko moduko kontzentrazioak zituen, \% 43k erretzaile pasiboa izateko moduko kontzentrazioak eta \% 45ean ez zen kotininarik antzeman, tabako-kearen esposiziorik gabeko maila, beraz. 
1. Taula: Laginaren deskribapena eta aldagai sozioekonomikoak

\begin{tabular}{|c|c|c|c|c|}
\hline Aldagaia & Kategoria & $\mathbf{N}$ & $\%$ & Galduak \\
\hline Umea & & 323 & 100 & \\
\hline \multirow[t]{2}{*}{ Sexua } & Neska & 162 & 50,2 & 0 \\
\hline & Mutila & 161 & 49,8 & \\
\hline \multicolumn{5}{|l|}{ Ama } \\
\hline \multirow[t]{4}{*}{$\begin{array}{l}\text { Adina haurdunaldiaren } \\
\text { hasieran }\end{array}$} & $<25$ & 6 & 1,9 & 0 \\
\hline & $25-29$ & 91 & 28,2 & \\
\hline & $30-34$ & 158 & 48,9 & \\
\hline & $35+$ & 68 & 21,1 & \\
\hline \multirow[t]{3}{*}{ Amaren ikasketa-maila } & Lehen maila edo ikasketarik gabe & 34 & 10,6 & 1 \\
\hline & Bigarren maila & 120 & 37,3 & \\
\hline & Unibertsitatea & 168 & 52,2 & \\
\hline \multirow[t]{3}{*}{ Amaren maila soziala } & KS I+II & 97 & 30,0 & 0 \\
\hline & KS III & 97 & 30,0 & \\
\hline & $\mathrm{KS}$ IV+V & 129 & 39,9 & \\
\hline \multicolumn{5}{|l|}{ Aita } \\
\hline \multirow[t]{3}{*}{ Aitaren ikasketa-maila } & Lehen maila edo ikasketarik gabe & 79 & 24,7 & 3 \\
\hline & Bigarren maila & 156 & 48,8 & \\
\hline & Unibertsitatea & 85 & 26,6 & \\
\hline \multirow[t]{3}{*}{ Aitaren maila soziala } & KS I+II & 87 & 27,2 & 3 \\
\hline & KS III & 48 & 15,0 & \\
\hline & $\mathrm{KS} I \mathrm{IV}+\mathrm{V}$ & 185 & 57,8 & \\
\hline
\end{tabular}

2. Taula: Tabakoaren esposizioa haurdunaldian INMA-Gipuzkoako emakumeengan; haurdunaldiaren aurretik, lehen seihilabetekoan eta 32. astean.

\begin{tabular}{|c|c|c|c|}
\hline Tabakoa & $\mathbf{N}$ & $\%$ & Galduak \\
\hline \multicolumn{4}{|c|}{ Haurdunaldiaren hasieran erretzen zuen } \\
\hline Ez & 247 & 78,7 & 9 \\
\hline Bai & 67 & 21,3 & \\
\hline \multicolumn{4}{|l|}{ 12. astean erretzen zuen } \\
\hline Ez & 272 & 86,9 & 10 \\
\hline Bai & 41 & 13,1 & \\
\hline \multicolumn{4}{|l|}{ 32. astean erretzen zuen } \\
\hline Ez & 281 & 88,1 & 4 \\
\hline Bai & 38 & 11,9 & \\
\hline \multicolumn{4}{|l|}{ Cotinina gernuan 32. astean } \\
\hline$<4 \mathrm{ng} / \mathrm{ml}$ (LOQ) & 131 & 44,7 & 10 \\
\hline $4-99 \mathrm{ng} / \mathrm{ml}$ & 127 & 43,3 & \\
\hline$\geq 100 \mathrm{ng} / \mathrm{ml}$ & 35 & 11,9 & \\
\hline
\end{tabular}

DSM-ADHD galdeketaren emaitzak 3. taulan ditugu. Banaketa ez-normala baina asimetrikoa sumatzen da, eskumara lerratutako banaketa. Aldi berean, laginaren gehienak, hiru laurdenak gutxienez, puntuazio txikia erakusten zuen bi azpieskalatan. 
3. Taula: DSM-ADHN galdesortaren sintomen puntuazio orokorraren parametroak, INMA-Gipuzkoako 4 urteko umeengan ( $\mathrm{N}=323$ ).

\begin{tabular}{|l|r|r|r|r|r|r|r|}
\hline $\begin{array}{l}\text { DSM-ADHN Galdesorta - } \\
\text { Eskala }\end{array}$ & $\begin{array}{c}\text { Batez } \\
\text { bestekoa }\end{array}$ & $\begin{array}{c}\text { Desbiderapen } \\
\text { estandarra }\end{array}$ & Minimoa & P25 & P50 & P75 & Maximoa \\
\hline Arreta-defizita & 2,7 & 3,9 & 0 & 0 & 1 & 4 & 21 \\
\hline $\begin{array}{l}\text { Hiperaktibitatea / } \\
\text { inpultsibotasuna }\end{array}$ & 2,5 & 3,8 & 0 & 0 & 1 & 4 & 27 \\
\hline ADHN & 5,2 & 6,9 & 0 & 0 & 3 & 7 & 46 \\
\hline
\end{tabular}

4. taulak ADHNaren lotura aldagai sozioekonomikoekin erakusten du. Mutilek bi azpieskaletan eta ADHN orokorrean puntuazio altuagoa edukitzeko arrisku handiagoa dute neskek baino, esanguratsua. Gurasoen ikasketak modu esanguratsuan lotzen dira ADHNaren puntuazioarekin; ikasketa baxuak dituztenean bi azpieskaletan eta, orokorrean, ADHN osoan, arrisku handiagoa ikusten da. Maila sozialarekin, berriz, lotura dago, baina ez da hain handia; aitek klase sozial baxua dutenean arreta-defizita esanguraz umeek arrisku handiagoa dute. Amaren adinak, ordea, ez du emaitza esanguratsurik erakusten.

Arreta-defizitaren diagnostikoa egiteko baldintza ( 6 sintoma edo gehiago) 3 mutilek betetzen zuten; neska batek eta bi mutilek hiperaktibitatearen diagnostikoa eta bi mutilek ADHN mota nahasia erakusten zuten. Guztira 8 ume; \% 2,5eko prebalentzia sumatzen da gure laginean, \% 0,6 neskengan eta $\%$ 4,3 mutilengan (ez da taulan azaltzen).

4. Taula: DSM-ADHN galdesortaren azpieskalak INMA-Gipuzkoako 4 urteko umeengan eta aldagai sozioekonomikoak. ORak eta \% 95 KTak.

\begin{tabular}{|c|c|c|c|}
\hline & \multicolumn{3}{|c|}{4 urte, DSM-ADHN } \\
\hline & Arreta-defizita & \begin{tabular}{|c|} 
Hiperaktibitatea / \\
inpultsibotasuna
\end{tabular} & ADHN \\
\hline \multicolumn{4}{|l|}{ Sexua } \\
\hline \multirow{2}{*}{$\begin{array}{l}\text { Neska } \\
\text { Mutila }\end{array}$} & 1 & 1 & 1 \\
\hline & $2,29(1,62-3,23)$ & $1,79(1,29-2,49)$ & $2,03(1,51-2,73)$ \\
\hline \multicolumn{4}{|l|}{ Amaren adina } \\
\hline \multirow{2}{*}{$\begin{array}{l}<29 \\
30-34\end{array}$} & 1 & 1 & 1 \\
\hline & $0,96(0,67-1,37)$ & $1,03(0,70-1,52)$ & $0,96(0,67-1,37)$ \\
\hline $35+$ & $0,87(0,56-1,34)$ & $1,00(0,62-1,62)$ & $0,87(0,56-1,34)$ \\
\hline \multicolumn{4}{|l|}{ Amaren ikasketak } \\
\hline \multirow{3}{*}{\begin{tabular}{|l} 
Lehen mailakoak \\
Bigarren mailakoak \\
Unibertsitatea \\
\end{tabular}} & 1 & 1 & 1 \\
\hline & $0,68(0,37-1,24)$ & $0,55(0,31-0,97)$ & $0,61(0,36-1,04)$ \\
\hline & $0,65(0,36-1,17)$ & $0,72(0,42-1,24)$ & $0,68(0,41-1,13)$ \\
\hline \multicolumn{4}{|l|}{ Aitaren ikasketak } \\
\hline \multirow{3}{*}{$\begin{array}{l}\text { Lehen mailakoak } \\
\text { Bigarren mailakoak } \\
\text { Unibertsitatea }\end{array}$} & 1 & 1 & 1 \\
\hline & $0,57(0,37-0,87)$ & $0,66(0,44-0,99)$ & $0,61(0,42-0,88)$ \\
\hline & $0,57(0,35-0,93)$ & $0,80(0,50-1,26)$ & $0,67(0,44-1,02)$ \\
\hline \multicolumn{4}{|l|}{ Amaren klase soziala } \\
\hline \multirow{3}{*}{$\begin{array}{l}\text { I-II (goikoa) } \\
\text { III } \\
\text { IV-V (behekoa) }\end{array}$} & 1 & 1 & 1 \\
\hline & $0,87(0,55-1,38)$ & $0,97(0,63-1,49)$ & $0,92(0,62-1,36)$ \\
\hline & $1,26(0,82-1,93)$ & $1,01(0,67-1,51)$ & $1,13(0,78-1,64)$ \\
\hline \multicolumn{4}{|l|}{ Aitaren klase soziala } \\
\hline \multirow{3}{*}{$\begin{array}{l}\text { I-II (goikoa) } \\
\text { III } \\
\text { IV-V (behekoa) }\end{array}$} & 1 & 1 & 1 \\
\hline & $0,99(0,55-1,78)$ & $0,64(0,37-1,11)$ & $0,79(0,48-1,30)$ \\
\hline & $1,55(1,02-2,36)$ & $0,93(0,63-1,38)$ & $1,20(0,84-1,71)$ \\
\hline
\end{tabular}


Tabakoak, bestalde, ez du emaitza esanguratsurik erakusten ADHNarekin edo azpieskalekin (5. taula). Arreta-defizita areagotzen da (\% 22 gehienez) ama erretzaileen kasuan, baina esangura estatistikora iritsi gabe. Tabakismo pasiboak, gernu-kotininaren arabera, ez du igotzen ADHNaren arriskua.

5. Taula: DSM-ADHN galdesortaren azpieskalak INMA-Gipuzkoako 4 urteko umeengan eta haurdunaldiko tabakoaren kontsumoa eta gernu-kotinina maila 32. astean. ORak eta \% 95 KTak.

\begin{tabular}{|c|c|c|c|}
\hline Tabakoa erretzen zuen & Arreta-defizita & $\begin{array}{l}\text { Hiperaktibitatea / } \\
\text { inpultsibotasuna }\end{array}$ & ADHN \\
\hline \multicolumn{4}{|l|}{ Haurdunaldiaren hasieran } \\
\hline Ez & 1 & 1 & 1 \\
\hline Bai & $1,22(0,79-1,90)$ & $1,04(0,61-1,78)$ & $1,15(0,66-2,01)$ \\
\hline \multicolumn{4}{|l|}{ 12. astean } \\
\hline Ez & 1 & 1 & 1 \\
\hline Bai & $1,17(0,77-1,76)$ & $1,04(0,63-1,71)$ & $1,07(0,64-1,81)$ \\
\hline \multicolumn{4}{|l|}{ 32. astean } \\
\hline Ez & 1 & 1 & 1 \\
\hline Bai & $1,20(0,82-1,74)$ & $1,04(0,66-1,64)$ & $1,11(0,69-1,79)$ \\
\hline \multicolumn{4}{|l|}{$\begin{array}{l}\text { Kotinina gernuan } 32 . \\
\text { astean }\end{array}$} \\
\hline$<4 \mathrm{ng} / \mathrm{ml}$ (LOQ) & 1 & 1 & 1 \\
\hline $4-99 \mathrm{ng} / \mathrm{ml}$ & $0,90(0,60-1,35)$ & $0,79(0,54-1,16)$ & $0,84(0,60-1,20)$ \\
\hline$\geq 100 \mathrm{ng} / \mathrm{ml}$ & $1,22(0,66-2,27)$ & $1,09(0,61-1,94)$ & $1,16(0,68-1,96)$ \\
\hline
\end{tabular}

\section{Eztabaida}

Ikerketa honen emaitzen arabera, mutilek ADHNa izateko arrisku handiagoa dute, arreta-defizitaren esparruan, batez ere. Arreta-defizitaren diagnostikoa egiteko baldintza 3 mutilek betetzen zuten, neska batek eta bi mutilek hiperaktibitatearen diagnostikoa eta bi mutilek ADHN mota nahasia erakusten zuten. Guztira \% 2,5eko prebalentzia sumatzen da gure laginean; \% 0,6 neskengan eta \% 4,3 mutilengan. Mundu-mailako prebalentziarekin (\% 5) alderatuz (1) lagin honetakoa baxua da. Hala ere, beste ikerketa batzuetako prebalentziak ez dira gurearen aldean hain ezberdinak: \% 1,7 (10), \% 2 (6), \% 2,1 (11) eta \% 2 (9). Autore horiek egindako ikerketetan, prebalentziaren datu baxua, laginaren adin txikiari atxikitu zioten (9). Izan ere, haurrak oso txikiak direnean (7 urte baino gutxiago), oraindik ez dute garatu ezaugarri nahikorik (DMS-IV eskaletan 6 sintoma baina gutxiago) ADHNaren diagnostikoa egin ahal izateko. Aipatutako azken ikerketa horretan 7 urtetik beherako haurren ADHNaren prebalentzia < \% 1 zen; aldiz, 14 urte inguru zituzten haurren ADHNaren prebalentzia \% 4,3ra igo zen. Kontuan hartuta gure populazioan ADHNaren diagnostikoa ezartzeko DMS-IV galdeketa haurrek 4 urte zituztenean egin zela, adin baxuari egotzi dakioke, neurri batean, prebalentzia baxua.

Horretaz gain, ikasketa gutxi duten gurasoen umeek ADHNaren puntuazio altuagoak edukitzeko probabilitate handiagoa dute. Aldi berean, eskulana (beheko maila soziala) duten aiten haurrek arrisku altuagoa azaldu dute arreta-defizita garatzeko. Bestalde, eskulana zuten amek 1,26ko $(0,82-$ 1,93) ORa aurkeztu zuten, esangura estatistikorik gabe, baina maila sozioekonomiko baxuarekiko lotura indartuz. Izan ere, ikerketa daniar batek maila sozial baxuarekin erlazionatzen zuen (6). Maila sozialarekin baino gehiago gure ikerketan ADHNa gurasoen ikasketa-maila baxuarekin lotzen da. Beste aldagai inportantea amaren adina izango litzateke. Gure emaitzetan ez da esangurarik sumatzen, baina kontuan izan behar dugu \% 2ra ez zirela iristen 25 urtetik beherakoak, aldakortasun txikia erakutsiz.

Ikerketa honetan, aldiz, ez da erlaziorik aurkitu ADHNaren eta haurdunaldiko tabakoaren artean. Arreta-defizitarekin aurkitutako ORak 1,17 eta 1,22 bitartekoak izan dira haurdunaldiko une ezberdinetan erretzearekin edo gernu-kotinina altuarekin. Badirudi ikerketa honek ez duela nahiko potentziarik izan lotura hori berresteko. Alde batetik, emakume gutxik aitortu zuten tabakoa erretzen zutela eta 32. astean erretzen zutenen artean gehienez egunean 12 zigarro erretzen zituztela aitortu 
zuten. Tabakoarekin OR altuagoak sumatu dira arreta-defizitarekin, hiperaktibitatearekin edo inpultsibitatearekin baino.

Hala ere, tabakoarekin lotura dagoela baieztatzen duten ikerketak daude $(5,8)$. Horiek beste portaera-arazo mota batzuk ere erlazionatu dituzte tabakoaren kontsumoarekin: agresibitatea eta jokaera antisozialak, portaera-arazo kanporakoiak direnak, eta portaera-arazo barnerakoiak diren antsietatea edo depresioa hain zuzen. Horren inguruan ikusi dute batez ere portaera kanporakoiekiko joera handiagoa dutela tabakoaren esposiziopean egon diren haurrek; baina ez dute hain garbi azaldu portaera barnerakoiekiko joera.

Bestalde, tabakoak garapen kognitiborako duen osagai kaltegarri garrantzitsuena nikotina dela adierazi dute ikertzaile ugarik $(6,10)$. Horren oinarria nikotinaren ordezkoek azaldu duten eraginean datza; ikusi baitute, ADHNa garatzeko arrisku berdina dutela tabakoa kontsumitzen duten amen haurrek eta nikotinaren ordezkoak (nikotina-txaplatak) erabiltzen dituzten amen haurrek. Nikotina kantitatea aztertuta, ikusi dute likido amniotikoan kontzentrazio handiagoak aurkitzen direla amaren odolean baino (8). Beraz, haurdun batek erretzen duenean, nikotinaren kontzentrazio handiagoa dago fetuan, amarengan baino. Nikotinaren esposizioak fetuarengan eragin ditzakeen kalteak ez dira berdinak haurdunaldiko hilabete guztietan. Izan ere, azken hiruhilekoan tabakoa kaltegarriagoa dela ikusi dute hasierako hiruhilekoetan baino $(6,10)$. Horrek, aipatutako ikerketaren arabera, denboratarte bateko aukera ematen dio amari erretzeari uzteko, haurrarentzat kaltegarria izan baino lehen. Horretaz gain, erlazioa dosiaren menpekoa dela azaldu dute (8); zenbat eta zigarro gehiago erre, gero eta arrisku handigoa izango du haurrak ADHNa izateko.

Ikerketa horien bide berdinetatik jarraituz, errebisio batean nikotinak garapen neurologikoan dituen efektuak azaltzen dira. Lan horrek dio nikotinaren efektua azetilkolinaren hartzaile nikotinikoetan gertatzen dela (8). Azetilkolinaren hartzaile horrek duen neurotransmisorea endogenoa da; azetilkolina hartzailearekin lotzean lortzen den aktibitatea garrantzi handikoa da burmuinaren heldutasuna lortzeko, fetu garaitik hasita, jaioberritan bai eta nerabezaroan ere. Izan ere, ikusi dute neurotransmisoreen (katekolamina, dopamina, norepinefrina eta azetilkolina) maila egokia beharrezkoa dela kortex prefrontalaren funtzionamendu optimorako. ADHNaren sintomak neurotransmisore horien funtzionamendu desegokiarekin erlazionatu dira. Horregatik, azetilkolinaren agonista exogenoa izanik, hartzaileari lotzen bazaio, azetilkolinaren funtzioa oztopatuko da. Horrek burmuinaren garapenean eragingo luke eta, aurrerago, aipatutako ADHNa bezalako portaera-azaroak izateko arriskua handituko litzateke (8). Gainera, arratoietan egindako ikerketetan ikusi zenez, tabakoaren kearen eraginpean egondako arratoiek (zigarro-pakete bat egunean, edo gutxiago) hiperaktibitatea eta agresibitatea bezalako portaera-arazoak azaltzen zituzten (batez ere arratoi arrek) (15).

Gure ikerketaren emaitzekin bat eginez, beste lan batean tabakoak ADHNaren garapenarekin zerikusirik ez duela ikusi da, baina mutilek neskek baino arrisku handiagoa dutela ADHNa garatzeko. Sexu-bereizketa horren arrazoia ingurune-faktoreen menpe bide dago; izan ere, mutilak ingurunefaktoreekiko sentikorragoak direla ikusi da neskak baino (3), eta ingurune-faktoreak ADHNaren erantzule garrantzitsua direla onartuz, mutilek ADHNa izateko arriskua handiagotua dago modu ez zuzenean.

Bestalde, 100.000tik gorako ume norvegiar ikertu dituen ikerketa baten arabera, familiaz kanpoko aldagaiak modu orokor batean kontuan hartzen direnean, badirudi ADHNa izateko arrisku handiagoa dutela tabako-esposizioa izan duten haurrek. Baina ikerketa familia barnean egiten denean nebaarreben artean, lotura hori kasu askotan desagertu egiten da (9). Horren inguruan, ikerketa ugari egin dira. Horietako ikerlan batzuk aitaren eta amaren tabakismoa kontuan hartuz egin dira. Horrela, ama erretzaileekin soilik (eta ez aita erretzaileekin) agertu denean, ADHNa izateko arriskuarekiko emaitza esanguratsua ezarri dute (5). Emaitza horren aurka beste ikerlan batzuetan $(9,11)$ bai amak eta bai aitak erretzen zuten egoeretan lotura agertu da. Baina lotura hori soilik mantentzen da aitak erretzen zuen familietan; hau da, ez dago ADHNa izateko arrisku handiagorik amak erretzen duen kasuan soilik. Horrek oinarri genetikoaren alde jotzen du, aitak ez baitu eragiten umetoki barneko ingurunean, baina elkarrekin banatzen ditu geneak eta beste ingurumen-faktore batzuk. Horrela, beste ikerketek tabakoaren eta ADHNaren arteko erlazio hori indargabetzen dute. Ildo beretik, 
oinarri genetikoa aztertu nahian, bi haurdunalditan zehar kontsumo ezberdina izan duen ama ikertzean (lehen haurdunaldian zehar erre du eta bigarren haurdunaldian ez du erre), ikusi da bi neba-arreben artean ez dagoela ezberdintasunik; hau da, esposizioa jasan duen haurrak ez duela arrisku gehiagorik ADHNa izateko, esposizioa jaso ez duenak baino (10). Horrek faktore genetikoen edo nahaste-faktoreen garrantziaz pentsarazten digu.

Bide beretik joanda baina metodologia desberdin bat erabiliz, haurdunaldian zeharreko tabakoaren eta ADHNaren arteko erlazioa faktore genetikoak bezalako nahasketa-faktoreen menpe zegoela azaldu nahian, genetikoki erlazioa zuten eta genetikoki erlaziorik ez zuten ama-haurrak aztertu zituen ikerketa batek (4). Hori egin ahal izateko, lagunduriko ugalketa bidez haurdun geratutako emakume talde bat (amarenak ez ziren obozitoekin ernaldutako fetuak lortuz) eta modu naturalean haurdun geratutako beste emakume talde bat elkarrekin konparatu zituzten. Ikerketa modu horretan egitean guztiz baztertzen da genetikak izan dezakeen eragina haurrak ADHNa garatzeko unean. Modu horretan, amaren tabakismoaren eta ADHNaren arteko lotura amarekin genetikoki erlazioa zuten haurren artean soilik ikusi zen eta genetikoki erlaziorik ez zutenen kasuan ez zen ADHNa izateko arrisku handiagorik ikusi, nahiz eta amak haurdunaldian zehar tabakoa kontsumitu. Hala ere, bi taldeetan esanguratsua izan zen haurraren pisu baxua: bai genetikoki lotura zutenek baita ez zutenek ere pisu baxua azaldu zuten tabakoarekiko eraginpean. Horrek bai azaldu dezake haurdunaldian tabakoa erretzearen eta jaiotzean haurraren pisu baxuaren arteko erlazioa. Orain arte ADHNaren eta haurdunaldian zeharreko tabakismoaren inguruan dauden ikerlanetako emaitza kontrajarriak ikusita, ondoriozta daiteke ez dagoela argudio nahikorik erlazio zehatz bat ezartzeko. Gainera, lehen aipatutako ikerketa norvegiarraren arabera, ADHNaren kasu kopurua hainbat urtetan zehar egonkor mantendu den bitartean, erretzaileen kopurua murrizten ari da. Benetan tabakoak ADHNaren garapenean eragina izango balu, bien prebalentziak proportzionalak lirateke eta ez alderantziz proportzionalak errealitatean gertatzen den moduan (9).

Laborategiko animaliekin egindako ikerketek erakutsi dute pakete baten pareko kea arnastutako arratoi arren ondorengoengan portaera-arazoak azaltzen zirela, hiperaktibitatea eta oldarkortasuna, besteak beste (15).

Lan honek hainbat muga ditu. Lagina ez da handia, $323 \mathrm{ama} /$ ume bikote. Baina txikiagoa da patologia duten haurrena, 8 guztira (prebalentzia \% 2,5ekoa, mundukoan aipatzen denaren erdia). Analisi estatistikoa sintomen puntuazioekin egin da, eta umeen laurdenak baino gehiagok ez du sintomarik. Tabako-kontsumoa ere urria zela ikusi da. Horrek guztiak lotura estatistikoak aurkitzeko oztopoak jarri dizkigu. Aurretik aipatu bezala, adin txikiegiko lagina izatea izan daiteke diagnostiko kopuru baxu horren arrazoia (9). INMAko kohortearen jarraipena ebaluatzean maila sozialean ezberdintasun esanguratsua zegoela ikusi zen: ikerketan jarraitzen zutenek maila sozial altuagoa eta goragoko ikasketak zituztela bertan behera uzten zutenek baino (12). Horrek ere eragina eduki zezakeen gure laginean aurkitu dugun tabako-azturan eta ADHNaren prebalentzia baxuan. Hala ere, ADHNaren diagnostiko kopurua handiagoa izan duten ikerketetan ere (11), ez da loturarik aurkitu.

Indarguneei dagokienez, esan beharra dago INMA proiektua kohorte prospektiboa dela, zeinean eremu sozioekonomiko eta ingurumen ezberdinetan bizi diren familien jarraipen zorrotza egiten den. Jarraipen horretan, ingurumen-datuak kontuan hartzeaz gain, hainbat galdesorta egiten dira denboran zeharreko ezaugarri fisiko, neurologiko eta sozioekonomikoen inguruko datuak jasotzeko. Gainera, aintzat hartzekoa da. orobat, informazioa modu objektiboan jaso dela, galdeketa hau pasatu baino lau urte lehenago. Tabakoaren kontsumoari buruz, galdesortako informazioa ez ezik, gernulaginetako kotinina-mailak ere neurtu ziren, emaitza subjektiboak datu objektiboekin kontrastatuz. Aipatu bezala, konkordantzia ona dago galdesortaren eta gernuko kotinina-mailaren artean. Emakume haurdunen \% $3 \mathrm{k}$ ez zuen tabako-aztura aitortzen eta gernuko kotinina-maila altua erakusten zuen; eta datu hori baxua da beste ikerketekin alderatuz gero (14). Horretaz gain, aldagai sozioekonomikoak hartu dira kontuan.

Sintesian, ikerketa honetan prebalentzia txikia sumatu da, \% 2,5ekoa eta mutilek ADHNa garatzeko arrisku handiagoa azaldu dute. Ikasketa-maila baxua duten gurasoen haurrek arreta-defizita eta hiperaktibitatea edo inpultsibitatea izateko arrisku handiagoa dute. 
Horretaz gain, gure ikerketan ez da aurkitu haurdunaldiko tabako-esposizioaren eta ADHNa garatzeko arriskuaren arteko erlazio esanguratsurik. Beste ikerketa batzuek azaldu duten harreman hori familia barnean parte hartzen duten nahaste-faktore ugarik azal dezakete, baina ez tabakoak umetoki barnean izan dezakeen eraginagatik. Horrela, ADHNaren eta haurdunaldiko tabakokontsumoaren artean lotura baldin badago ere, txikia dela erakusten du gure ikerketak.

Gai honen inguruan jardun diren ikertzaile gehienek dioten bezala, ikerketa ezberdinen emaitza kontrajarriak ikusita, ikerketa gehiago behar dira tabakoaren eta ADHNaren arteko lotura finkatzeko.

\section{Erreferentzia bibliografikoak}

1. Silva D, Colvin L, Hagemann E, Bower C. Environmental risk factors by gender associated with attention-deficit/hyperactivity disorder. Pediatrics. 2014 Jan;133(1):e14-22.

2. Rodillo $E$. Trastorno por déficit de atención e hiperactividad (TDAH) en adolescentes. Rev Med Clin Condes. 2015; 26: 52 - 59.

3. Biederman J, Fitzgerald M, Spencer TJ, Bhide PG, McCarthy DM, Woodworth KY, Saunders A, Faraone SV. Is Paternal Smoking at Conception a Risk for ADHD? A Controlled Study in Youth With and Without ADHD. J Atten Disord [Internet]. 2017 Feb 2 [cited 2017-1006]:1:1087054717690809. Available from: https://doi.org/10.1177/1087054717690809

4. Thapar A, Rice F, Hay D, Boivin J, Langley K, van den Bree M, Rutter M, Harold G. Prenatal smoking might not cause attention-deficit/hyperactivity disorder: evidence from a novel design. Biol Psychiatry. 2009 Oct 15;66(8):722-7.

5. Keyes KM, Davey Smith G, Susser E. Associations of prenatal maternal smoking with offspring hyperactivity: causal or confounded? Psychol Med. 2014; 44: 857 - 867.

6. Zhu JL, Olsen J, Liew Z, Li J, Niclasen J, Obel C. Parental smoking during pregnancy and ADHD in children: the Danish national birth cohort. Pediatrics. 2014 Aug;134(2):e382-8.

7. Joelsson P, Chudal R, Talati A, Suominen A, Brown AS, Sourander A. Prenatal smoking exposure and neuropsychiatric comorbidity of ADHD: a finnish nationwide population-based cohort study. BMC Psychiatry. 2016 Aug 31;16:306.

8. Tiesler $\mathrm{CM}$, Heinrich J. Prenatal nicotine exposure and child behavioural problems. Eur Child Adolesc Psychiatry. 2014 Oct;23(10):913-29.

9. Obel C, Zhu JL, Olsen J, Breining S, Li J, Grønborg TK, Gissler M, Rutter M. The risk of attention deficit hyperactivity disorder in children exposed to maternal smoking during pregnancy - a reexamination using a sibling design. J Child Psychol Psychiatry. 2016 Apr;57(4):532-7.

10. Obel C, Zhu JL, Olsen J, Breining S, Li J, Grønborg TK, Gissler M, Rutter M. The risk of attention deficit hyperactivity disorder in children exposed to maternal smoking during pregnancy - a reexamination using a sibling design. J Child Psychol Psychiatry. 2016 Apr;57(4):532-7.

11. Langley K, Heron J, Smith GD, eta Thapar A. Maternal and paternal smoking during pregnancy and risk of ADHD symptoms in offspring: testing for intrauterine effects. Am J Epidemiol. 2012 Aug 1;176(3):261-8.

12. Guxens M, Ballester F, Espada M, Fernández MF, Grimalt JO, Ibarluzea J, Olea N, Rebagliato $M$, Tardón A, Torrent M, Vioque J, Vrijheid M, Sunyer J. Cohort Profile: the INMA--INfancia y Medio Ambiente--(Environment and Childhood) Project. INMA Project. Int J Epidemiol. 2012; 41 : 930 940.

13. American Psychiatric Association. Diagnostic and Statistical Manual of Mental Diseases: DSM-IV. 4th ed. Washington, DC: American Psychiatric Association; 1994. $886 \mathrm{p}$

14. Aurrekoetxea JJ, Murcia M, Rebagliato M, López MJ, Castilla AM, Santa-Marina L, Guxens M, Fernández-Somoano A, Espada M, Lertxundi A, Tardón A, Ballester F. Determinants of selfreported smoking and misclassification during pregnancy, and analysis of optimal cut-off points for urinary cotinine: across sectional study. BMJ Open. 2013; 3: e002034.

15. Yochum C, Doherty-Lyon S, Hoffman C, Hossain MM, Zelikoff JT, Richardson JR. Prenatal cigarette smoke exposure causes hyperactivity and aggressive behavior: role of altered catecholamines and BDNF. Exp Neurol. 2014 Apr;254:145-52. 